\title{
CREATING A VARISTOR BASED ON ZINC OXIDE (ZnO) POWDER, OBTAINED BY PLASMA DYNAMIC METHOD
}

\author{
K. Firsov ${ }^{a}$, A. Sivkov ${ }^{b}$, Y. Shanenkova ${ }^{c}$ \\ National Research Tomsk Polytechnic University

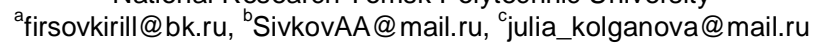

Zinc Oxide $(\mathrm{ZnO})$ is a perspective material. This paper shows the results on synthesis of hexagonal zinc oxide and it's application.

Keywords: hexagonal zinc oxide, nanoparticles, single-crystalline particle structure, synthesis, plasma accelerator

Zinc oxide is well-known material having good properties. Its application fields are wide including medicine, cosmetology, chemical industry, pharmaceutics, spintronic etc. In electrical power engineering, ZnO can be used as varistor due to its semiconductor properties that makes it prospective for applying in modern surge arresters. At present, there are many methods for obtaining $\mathrm{ZnO}$ powders such as chemical, hydrothermal, thermal and others [1-3].

This work shows a unique method for obtaining ultradispersed ZnO powders with hexagonal structure in a highspeed pulse plasma jet, which is generated by coaxial magnetoplasma accelerator (CMPA) [4].

The synthesized material was studied by few methods such as X-ray diffractometry (XRD) analysis using a Shimadzu XRD 7000S diffractometer with CuKa radiation as well as transmission electron microscopy (TEM) method with the help of a Philips CM12 microscope. The XRD data were identified in accordance with PDF-2 database using the "SearchMatch" software. After studying the obtained powdered product, it was used to sinter a bulk sample using a spark plasma sintering (SPS) method (Advanced Technology SPS 10-4 setup). The polished section of the obtained bulk sample was made in order to study its microstructure. For this, a Hitachi TM3000 scanning electron microscope was used.

Figure 1 shows a typical XRD-pattern of the obtained product and the results of the transmission electron microscopy analysis. It can be seen that all reflexes of this product (fig.1a) are in a good agreement with reflexes of the reference card for zinc oxide with hexagonal syngony of space group P63mc (no.186) both as for peak intensities and as for their position on $2 \theta$ axis. According to the reference card data (ICDD card No. 36-1451), the parameters of crystalline lattice are as follows $\mathrm{a}=\mathrm{b}=3.24982 \AA$, $\mathrm{c}=5.20661 \AA$ (Fig. 1b). According to the obtained TEM-images, it is seen that crystalline particles in the product have a single-crystalline structure with normal hexagonal syngony, which was also found by XRD analysis of the synthesized material. The dark field images, obtained in the light of reflexes from the pointed interplanar distances, also clearly indicate the presence of hexagonal $\mathrm{ZnO}$ particles in the product.
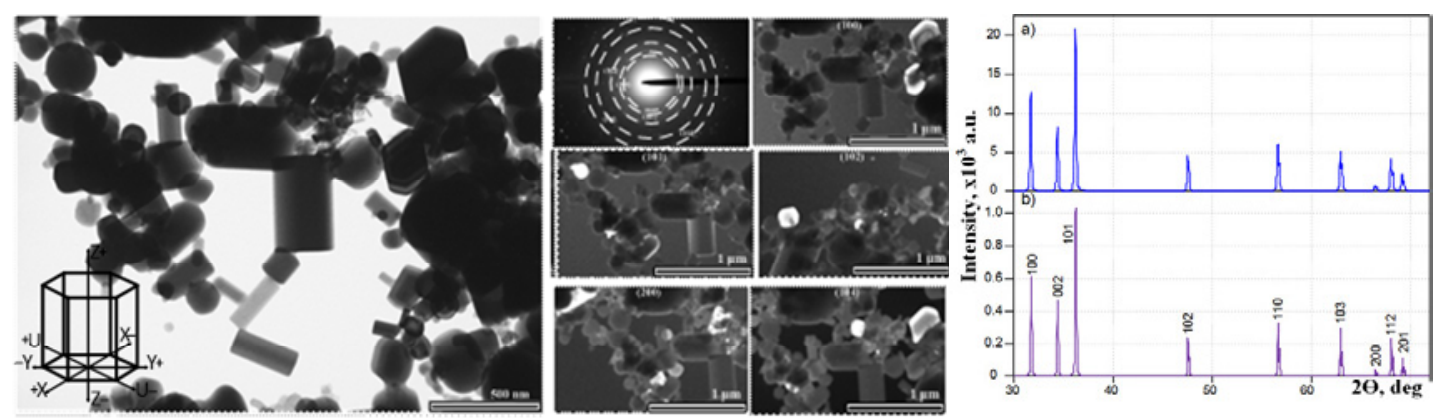

Fig. 1. a) Bright-field and dark-field TEM-images; b) Typical XRD-patterns of product of plasma dynamic synthesis and reference structural model of hexagonal zinc oxide
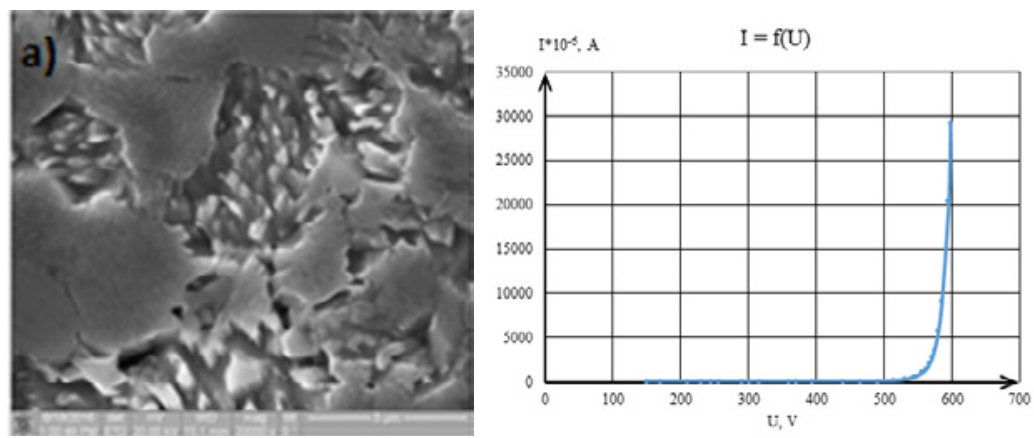

Fig. 2. a) SEM-images of the obtained ceramics polished sections of etched surface; b) Sample UI characteristic 
After having been studied, the powdered product was sintered using the SPS-setup at the pressure of $60 \mathrm{MPa}$ and the speed of hitting at $800{ }^{\circ} \mathrm{C} / \mathrm{min}$ until reaching the maximum temperature of $1100{ }^{\circ} \mathrm{C}$. The obtained sample was investigated using scanning electron microscopy. In order to better study the morphology, the obtained ceramics sample was additionally etched. The surface of the polished section is shown in Figure 2.

It is worth noting that the wide particle size distribution in the synthesized product positively influences the obtaining of high-density ceramics. The etched surface shows that ceramics microstructure consists of the parallel micron crystallites with acicular shape, which is typical for zinc oxide with the hexagonal syngony (Fig. 2a). These and other SEM-image show the cuts (in the plane of polished section) of elongated $\mathrm{ZnO}$ nanocrystals, $\mathrm{Z}$ axis of which in crystallographic direction are almost congruent with direction of pressing.

In order to investigate the possibility to use this product as surge arrester (varistor), a volt-ampere (UI) characteristic was obtained (Fig. 2b). According to measured UI curve, the obtained sample has a nonlinear properties. When current is $1 \mathrm{~mA}$, voltage is $\sim 550 \mathrm{~V}$ that makes it acceptable for using as varistor.

In this work, it was proved that single-crystalline hexagonal zinc oxide with a high purity can be synthesized using the system based on the coaxial magnetoplasma accelerator. The sintered ceramics, consisting of this powder, has high enough density up to $99.9 \%$ that is achieved by the presence in the synthesized products of particles with wide size distribution. Nonlinear character of UI characteristic confirms the possibility to use it as a varistor.

The work was performed under Grant of the President of Russian Federation SP-1179.2015.1

\section{References}

1. Sazonov R., Kholodnaya, Ponomarev D. et al. Plasma-chemical synthesis of composite nanodispersed oxides // Journal of the Korean Physical Society. - 2011, Dec. - Vol. 59, No. 6. - P. 3508-3512;

2. Nolan N.T. Sol-gel synthesis and characterisation of novel metal oxide nanomaterials for photocatalytic applications. - Dublin Institute of Technology;

3. A.B. Djurisic, X. Chen, Y.H. Leunga et al. ZnO nanostructures: growth, properties and applications // Journal of Materials Chemistry - 2012, Jan. - Vol. 17.

4. Sivkov A., Ivashutenko A., Shanenkova Y. et al. Plasma dynamic synthesis and obtaining ultradispersed zinc oxide with singlecrystalline particle structure // Advanced Powder Technology. - 2016. - Vol. 27. - P. 1506-1513. 